by D.C. Findlay

\title{
A world organization of geological surveys?
}

The roles of geological surveys are changing rapidly in a rapidly changing world. Beset by shrinking operating resources and critical scrutiny over the relevancy of traditional programs, these surveys face increasing pressures to respond more effectively to the current needs of society. These needs are driving surveys to provide leadership in the application of geoscience knowledge in order to address social and environmental questions, as well as in the more traditional economic applications to resource development.

These and related issues were discussed at the International Conference of Geological Surveys, which was organized by the Geological Survey of Canada in Ottawa, Ontario, Canada, in April 1992 as part of its 150th anniversary celebrations. As the discussion at this conference showed, the roots of many of the issues facing geological surveys are global in nature, although their immediate impacts may be local or regional. In both formal and corridor discussions, two dominant views emerged. The first was that all geological surveys will have to move to respond quickly to the priorities of the environmental agenda. The second was that, in order to contribute effectively toward solutions to environmental problems, geological surveys will have to develop better methods of communication, particularly communication upward to their policymaking and political levels.

Factors such as the above suggest that the time may be appropriate for geological surveys and related agencies to establish better communication networks on a global scale. One mechanism for this would be the formation of a world organization of geological surveys. This question was discussed in a preliminary manner at the conference. Further discussions on the topic are planned for the 29th International Geological Congress in Kyoto, Japan.

\section{Introduction}

In April of 1992, the Geological Survey of Canada convened the International Conference of Geological Surveys around the general theme of "National Geological Surveys in the 21 st Century." Known now by the acronym ICOGS, the conference was designed to serve two purposes. First, the Geological Survey of Canada (GSC), as a part of its 150th anniversary celebrations, wished to organize and host an international gathering that would place a spotlight on some of the challenges facing a modern geological survey. Secondly and equally important, based on conversations with colleagues in sister agencies around the world, the feeling at the GSC was that the problems and challenges facing geoscience organizations everywhere are remarkably similar and are pressingly urgent. Thus, the occasion of the GSC's 150th anniversary might serve as a timely point of departure for discussion of these topics by representatives of national and State and Provincial geological surveys and related geoscience agencies and institutions from around the world.

The overall focus of ICOGS was summed up by Ken Babcock. Assistant Deputy Minister, Geological Survey of Canada, in the foreword to the ICOGS Program and Abstracts booklet:

In a world that is changing quickly, geological surveys from all nations are facing many new challenges. . . The need for innovative and practical strategies for the future is pressing, and it is clear that these can be best developed through direct discussion among all concerned parties. In this context, geological surveys around the world should have much to learn from each other's expericnces and traditions. Our hope is that this conference will provide a suitable forum to stimulate a dynamic interchange of ideas. .

The consensus of both the organizers and participants at ICOGS was that the conference did succeed in providing a "suitable forum to stimulate . . ideas." The main question that flows from ICOGS is how to continue this process.

From the beginning, a central concept in ICOGS was the question of whether the conference could serve as a springboard for establishing a world committee or organization of geological surveys. This question was on the ICOGS agenda and served as the focus for the closing plenary discussion. Opinion was mixed, but sufficient interest was expressed among participants to take the question to the next stage. This will be the subject of a general discussion that will take place during the International Geological Congress (IGC) in Kyoto, Japan. In this article, I summarize the main discussions at ICOGS and, within that context, address some of the elements of the question of a world organization.

\section{International Conference of Geological Surveys}

\section{Organization and content}

ICOGS was held April 12-14, 1992. The 175 invited participants represented national and State and Provincial geological surveys, geoscience research institutions, industry (Canadian and foreign), academia, and international scientific organizations including the International Union of Geological Sciences (IUGS), the International Geological Correlation Programme (IGCP), and the United Nations Educational, Scientific, and Cultural Organization (UNESCO). Participants included 17 heads of national geological surveys, as well as a dozen heads of State and Provincial surveys (mainly Canadian). 
Table 3.-Principal objectives of ICOGS

(1) To contribute to the 150th anniversary events of the Geological Survey of Canada.

(2) To discuss some major geoscience themes of the next 10-15 years, particularly as they relate to the work of geological surveys.

(3) To compare views on these themes among national and regional geological surveys.

(4) To explore community responses to geoscience challenges, including the feasibility of a world organization of geological surveys.

Finally, the theme of communication and collaboration emerged strongly across the board. There is a general perception that geological surveys have not been particularly successful in communicating the nature of their business and its products, both at the policy and political levels and at the level of general public information. There is also a perception that the survey community has been focused inward and has been overly preoccupied with defending traditional tenets and institutional "cultures," as well as insufficiently sensitive to the real needs of its public and private sector clients. Whether or not such perceptions are of doubtful authenticity, the reality is changing rapidly. Public information, education, and outreach programs are now high on the agendas of most surveys. Communications, especially "political" communications, are recognized universally as important. Forging alliances with other organizations and institutions, both public and private, has become part of the stock-in-trade of most modern, client-oriented organizations, and geological surveys are no exception. In the end, it is this coupling of an organizational outward focus and the recognition that many of the major environmentally related geoscience issues are truly global in impact that drives consideration of the need for a network linking the world community of geological surveys.

\section{Elements of a world organization of geological surveys}

The organizers of ICOGS had much of the foregoing in mind when the question of a world organization was included in the conference program. Prior to the meeting, a sounding of selected colleagues at various institutions around the world had drawn a generally positive response, although some respondents had reservations about the practicability of such an organization, primarily because of the numbers and logistics that would be involved. It was recognized that some precedent exists in these matters, at least in Europe, through the experience of the Western Europe Geological Surveys (WEGS) organization. The discussions at ICOGS seemed, at least in retrospect, to have crystallized the impression that a collective mechanism for information exchange and for informed advice and consultation amongst geological surveys will be, ultimately, inevitable. In his concluding remarks at ICOGS, Ray Price placed the matter in elegant perspective:

I suggest that if we want to be forward-looking, we must not simply respond to the presently identified demands of [those] customers, but . . . [we must] look forward and identify emerging needs on the part of our customers, our people, and our governments, help them to see their future needs, and help them to meet their future needs. This is the leadership component. It think it's a leadership challenge for every individual geological survey and collectively for all the geological surveys of the world.

In a proposal presented at the ICOGS closing plenary session for consideration of a world organization, I first reviewed the overall objectives of the conference (table 3 ). Objective 4 was "to explore community responses to geoscience challenges" through mechanisms that could include a world organization. Following this, I listed some of the more obvious arguments for and against such a concept, none of which in themselves were particularly new or original. However, in total, there seem to be some valid reasons why such an organization could be practical and, ultimately, beneficial to the community at large. After reflecting on the discussions at ICOGS and after further discussions with colleagues at the GSC and elsewhere, I feel strongly that the pressures that will bear over the next few years on the geoscience community in general-and on governmental geoscience organizations in particular-may lend more urgency to the matter than we originally anticipated.

Table 4 lists some of the possible objectives of a potential charter for a world organization of geological surveys. Although the wording may be inexact, the first objective is intended to capture exactly the kind of charge that Ray Price referred to in his remarks quoted above.

The second component of the potential charter seems critical in terms of complementing, rather than setting out to duplicate, the already extensive, global, nongovernmental geoscience network. In the end, however, the third element (or a variant thereof) is probably the most compelling from a practical standpoint. We are all familiar with the communication advantage provided by networks at a variety of levels, both formal and informal. The establishment of such a continuing network at senior levels of survey organizations around the world, as well as the conscious maintenance of such a network through periodic meetings or meetings of opportunity held on the occasion of other geoscience gatherings, could, it may be argued, contribute significantly to the overall effectiveness of international geoscience.

Table 4. $-A$ world organization of geological surveys? A potential charter

(1) To provide collective leadership in guiding the application of governmental geoscientific knowledge and expertise in order to address the major social and environmental problems affecting the human condition.

(2) To provide a mechanism for fostering communication and collaboration among major international nongovernmental scientific organizations, such as IUGS, International Council of Scientific Unions (ICSU), and International Union of Geodesy and Geophysics (IUGG), and social, economic, and development organizations, such as UNESCO, United Nations Environment Programme (UNEP), and United Nations Development Programme (UNDP).

(3) To provide a global network for consultation, development of consensus views on major issues, and timely exchange of advice and opinions at senior levels within the world's geological survey organizations.

(4) To facilitate and promote the development of major transnational projects that would require the support of a number of government agencies in order to be feasible.

(5) To facilitate the development of multilateral memorandums of understanding (MOUs) or other instruments that could serve as enabling mechanisms for regional and international cooperation in geoscience projects, as in item 4 above.

(6) To serve as a clearinghouse for information (Secretariat function); to facilitate the exchange of data, information, and staff amongst participating countries and agencies; and to develop and promote training and technology transfer programs. 
In discussions on this third element at ICOGS, three views emerged. One was that such a world organization might be mounted as a constituent Commission under the auspices of IUGS. A second view was that a loose, informal "club" might suffice, one that could seize opportunities from time to time for gathering representatives from surveys to discuss current events, much as the manner of ICOGS. Finally, the third point of view is the one expressed in this article: that the time and circumstances are appropriate to pursue the question of a formal global network of geological surveys as an independent organization, but one having obvious and collaborative ties to other international geoscientific organizations such as IUGS.

\section{Conclusion}

ICOGS focused attention on issues facing geological surveys in a rapidly changing world. Clearly, many surveys are dramatically shifting their traditional roles and tenets in order to accommodate change. It also seems that the collective responsibilities and capacities of geological surveys could be enhanced through the establishment of a world organization of geological surveys, so that geoscience knowledge could be applied more successfully to addressing societal needs. This proposition will be discussed further at a special meeting of interested delegates at the 29 th IGC in Kyoto.

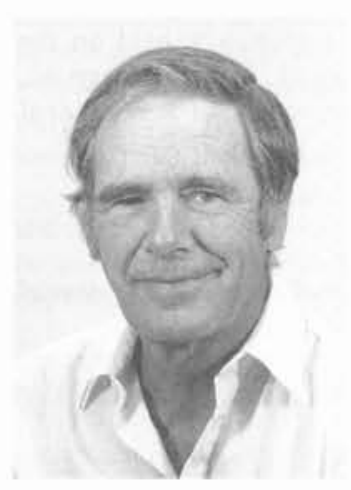

Dr. D.C. (Chris) Findlay is Director General of the Minerals and Continental Geoscience Branch of the Geological Survey of Canada (601 Booth Street, Ottawa, Ontario K1A OE8, Canada). He originated the concept of ICOGS and served as General Chairman of the Ottawa conference. $\mathrm{He}$ is past Chairman of the IUGS and UNESCO Deposit Modeling Program and currently serves on the Steering Committee for the program. Formerly, he pursued research interests in ultramafic rocks throughout Canada. 